\title{
Stainless Steel Microstructural Evolution of Hot-Rolled Clad Plate
}

\author{
Hai-Bin LI ${ }^{1,2}$ *, Qing-Xue HUANG ${ }^{2}$, Cun-Long ZHOU ${ }^{2}$, Guang-Ming LIU ${ }^{2}$, Qin MA ${ }^{1}$ \\ ${ }^{1}$ School of Material Science and Engineering, Lanzhou University of Technology, Lanzhou 730050, China \\ ${ }^{2}$ College of Material Science and Engineering, Shanxi Provincial Key Laboratory of Metallurgical Device Design Theory \\ and Technology, Taiyuan University of Science and Technology, Taiyuan 030024, China \\ cross'ref http://dx.doi.org/10.5755/j01.ms.22.4.12828
}

Received 01 August 2015; accepted 15 January 2016

\begin{abstract}
The stainless steel microstructure evolution of carbon-stainless-clad steel plate was investigated during vacuum hot-rolling bonding under different deformation conditions. The results show that carbide $\mathrm{M}_{2} \mathrm{C}$ precipitates in the interior of stainless steel (SS) and carbon content increases with rising reduction ratio $(\varepsilon)$. The dislocation density of the SS surface $\left(\rho_{\mathrm{I}}\right)$ is lower than that of the midst $\left(\rho_{\mathrm{M}}\right)$, and $\rho_{\mathrm{I}}$ decreases with the rising $\varepsilon$. However, $\rho_{\mathrm{M}}$ increases first and then decreases with rising $\varepsilon$. The dislocation density of bonding interface decreases due to the increasing size of austenite grain. Furthermore, the dislocation density of the midst is high where the high energy of carbide $\mathrm{M}_{2} \mathrm{C}$ is concentrated for single-pass rolling, and the quantity of $\mathrm{M}_{2} \mathrm{C}$ increases with reduction ratio. Moreover, carbide almost disappeared while being transformed into austenite, and only minimal granular carbides were formed after two-pass rolling. Bonding strength increases evidently with rising $\varepsilon$ and is inversely proportional to $\rho_{\mathrm{I}}$.

Keywords: hot-rolling bonding, austenitic stainless, reduction ratio, microstructure, phase transformation.
\end{abstract}

\section{INTRODUCTION}

Stainless steel (SS)/carbon steel (CS)-clad plate is bonded through a specific approach, in which carbon steel is the substrate and stainless steel is the clad layer. This approach is widely used in the petroleum and chemical industries [1]. The approach not only takes advantage of the good toughness, corrosion resistance, and appearance of SS but also possess the high strength and low-cost of $\mathrm{CS}$, which presented a dramatically increasing demand in recent years [2]. At present, the main method for producing the clad plate is explosion rolling. However, clad plates could not be manufactured at a large scale because of the restriction of production technology, such as severe pollution, high cost and the limited size of the clad plate [3]. Moreover, product quality has received considerable attention because of shrinkage cavity, cracks and stomata of the bonding interface under explosive blast wave [4]. Hot-rolling bonding has attracted wide interest. The approach offers advantages of economy and efficient production capacity, less pollution and low energy consumption $[5,6]$. However, the binding rate, bond quality and heat treatment process present certain deficiencies under production technology $[7,8]$. The interface is easily oxidized at high temperature, which incurs reduced strength of the composite interface. To effectively prevent oxidation, vacuum hot-rolling bonding (VHRB) has been applied [9]. Two kinds of steels are all-around welded, generating clad billets after vacuum pumping. In addition, previous studies were mostly concerned about bonding interface characterization, and the microstructures of the clad plate have seldom been reported.

\footnotetext{
* Corresponding author. Tel.: +86-13633473659.

E-mail address: lihaibin19750300@sina.com (H.B. Li)
}

The base and the flyer materials utilized in this study were carbon steel (Q235A) and austenitic stainless steel (304). The plate thickness was $5.5 \mathrm{~mm}$ for CS and $2 \mathrm{~mm}$ for SS. The main chemical compositions of the SS were $\mathrm{C}(0.03 \%), \quad \mathrm{Si}(0.43 \%), \quad \mathrm{Mn}(1.21 \%), \quad \mathrm{Cr}(18.23 \%)$, $\mathrm{Ni}(8.03 \%)$ and $\mathrm{Fe}$ (Bal.). Microstructure evolution and transformation behaviour of SS were observed by optical microscopy (OM) and scanning electron microscopy (SEM). Furthermore, the mechanical properties of the carbon-stainless clad steel plate under different deformation conditions were studied.

\section{EXPERIMENTAL DETAILS AND RESULTS}

The specification of four-ply bond billets was $150 \mathrm{~mm} \times 125 \mathrm{~mm} \times 15 \mathrm{~mm}$. Fig. 1 shows a schematic of bond billet fabrication. The non-binding surface of the two adjacent surfaces of SS in clad plate was coated with release agent for smooth separation of the two clad plates after symmetrical rolling.

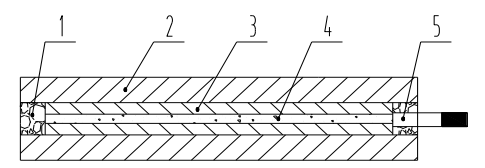

Fig. 1. The diagram of experimental sample preparation: 1 -welded seam; 2 -carbon steel; 3-stainless steel; 4 -release agent; 5 -the pipe of vacuum-pumping

The billets were heated to $1300{ }^{\circ} \mathrm{C}$ and soaked for $15 \mathrm{~min}$ in the heating furnace. This step was immediately followed by one-passing or two-passing on a two-high reversible mill (with a roller diameter of $360 \mathrm{~mm}$ ) at a rolling speed of $0.1 \mathrm{~m} / \mathrm{s}$. The pre/post-rolling upper surface temperature of clad plate was checked by the TI300 and AR892 non-contact infrared temperature measurement instrument. Different rolling technologies are shown in Table 1. 


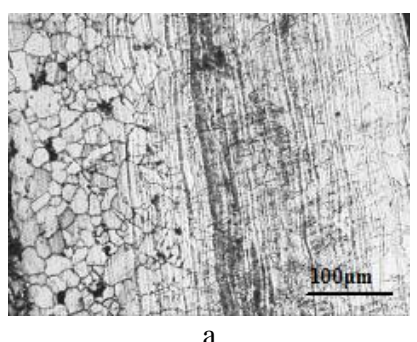

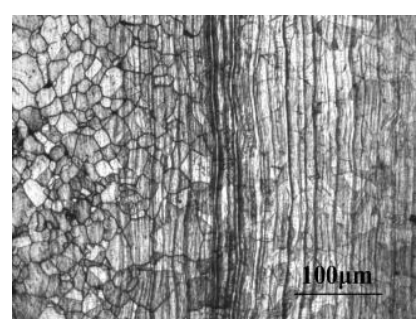

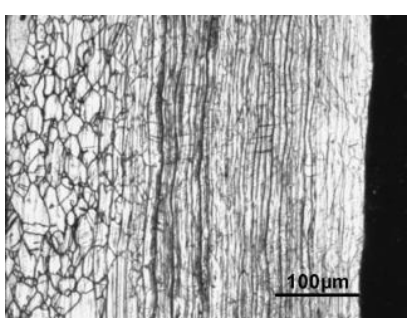

c

Fig. 2. OM micrograph of SS: $a-$ sample $1^{\#} ; \mathrm{b}$-sample $2^{\#}$, c-sample $3^{\#}$

The clad plate was cooled in air to room temperature. A small sample was cut from each billet along the rolling direction, and the samples were fabricated into a metallographic specimen with $22 \mathrm{~mm}$ diameter by metallographic specimen inlaying machine. The specimens were ground and polished following standard metallographic procedures. Then, SS side was etched in an aqueous solution $\left(18 \mathrm{~g} \mathrm{FeCl}_{3}+30 \mathrm{~mL} \mathrm{HCl}+100 \mathrm{~mL} \mathrm{H}_{2} \mathrm{O}\right)$ for $10 \mathrm{~s}$. Microstructures were revealed by OM and SEM (model S4800 type) equipped with energy dispersive spectroscopy (EDS). Shear tests were conducted in accordance with the national standard, and the shear strength of SS/CS clad plate was calculated from the test result by WDW-100 electronic universal tensile testing machine.

Table 1. Rolling processes of clad plates

\begin{tabular}{|c|c|c|c|c|c|}
\hline No. & $\begin{array}{c}\text { Rolling } \\
\text { force, } \mathrm{T}\end{array}$ & Pass & $\begin{array}{c}\text { Pre/post-rolling } \\
\text { temperature, }{ }^{\circ} \mathrm{C}\end{array}$ & $\begin{array}{c}\text { Pre/post-rolling } \\
\text { temperature, }{ }^{\circ} \mathrm{C}\end{array}$ & $\begin{array}{c}\text { Reduction } \\
\text { rate, } \%\end{array}$ \\
\hline $1^{\#}$ & 40 & 1 & $1084 / 981$ & - & 20 \\
\hline $2^{\#}$ & 39 & 1 & $1188 / 1050$ & - & 30 \\
\hline $3^{\#}$ & $38 / 38$ & 2 & $1193 / 1008$ & $981 / 973$ & $30 / 20$ \\
\hline
\end{tabular}

\subsection{Surface microstructures}

Fig. 2 a shows the microstructure of SS. The figure shows that the clear austenite at the left side is adjacent to the non-bonding interface, and the black ribbons that are parallel to the rolling direction in the midst of SS layer are clear and dense. However, the austenite and ribbons of the bonding interface are all obscured at the right of the figure. Similarly, in Fig. 2 b, the austenite is adjacent with the non-bonding interface, and the black ribbons are mostly concentrated in the middle of the SS layer when the reduction ratio $(\varepsilon)$ is $30 \%$. However, the ribbons are clearer and denser than the former. The range of austenite was reduced, whereas the black ribbon area increased in contrast. In addition, the ribbon coexists with austenite at the bonding interface. Fig. $2 \mathrm{c}$ shows that the $\varepsilon$ increases to $44 \%$. We can observe that the austenite region decreases monotonously to $100 \mu \mathrm{m}$ after two-pass rolling, whereas, the black ribbons are coarser than the others, and the density of the ribbons in the middle of the SS layer is the highest. Austenite and ribbons are all blurred in the $3^{\#}$ bonding interface. Moreover, in the adjacent regions between ribbon and austenite, both structures are not independent but coexisting. The black area at the right of Fig. $2 \mathrm{c}$ is the CS matrix, which is extremely etched by the aqueous solution of $\mathrm{FeCl}_{3}$.

\subsection{Middle microstruture}

The dense ribbons area in the middle of specimens is observed by using OM. A clear image of the sample by single-pass rolling, instead of the blurred black ribbon is observed by SEM with super depth of field. In the local area, however, the specimen surface formed dark and light ribbons at the reflected light of different angles when the grain is seriously etched to evident uneven surfaces after two-pass rolling. For example, the black ribbon is the sunken area, and the light ribbon is the protuberant area, as shown in Fig. 3.

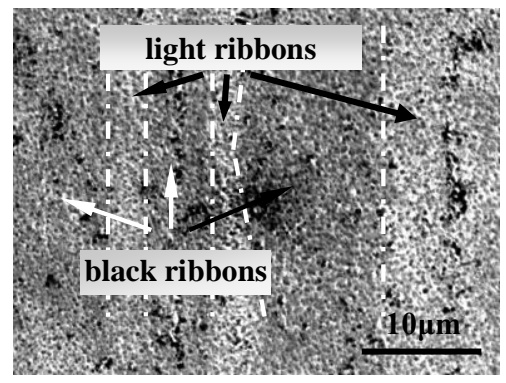

Fig. 3. Dense ribbons of the middle of SS plate

The micrographs of the dense ribbon area in the middle of the SS layer are revealed by SEM (as shown in Fig. 4). The streaks with different lengths (I) precipitated in certain austenite grains, as shown in Fig. 4(a), where the elements are mainly $\mathrm{C}, \mathrm{Cr}$ and $\mathrm{Fe}$ as was defined by EDS. The carbon content of the streaks (I) is shown in Table 2.

Fig. $4 \mathrm{~b}$ shows the short streaks (II) precipitated in the austenite grain with the increase in $\varepsilon$. However, the carbon content of the grains reaches up to $25.67 \%$. The content of short streaks (II) is shown in Table 2.

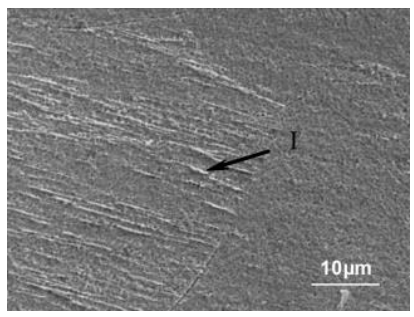

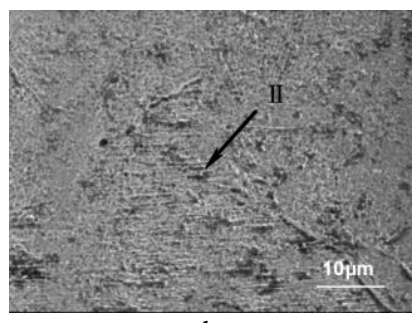

b

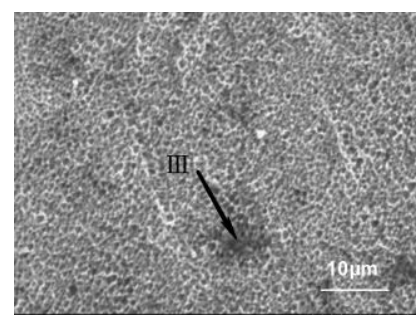

Fig. 4. Microstructure of the dense ribbons area: a-sample $1^{\#} ; \mathrm{b}-$ sample $2^{\#}, \mathrm{c}-$ sample $3^{\#}$ 
Fig. $4 \mathrm{c}$ shows the fine and well-distributed austenite grain in the ribbon area when the $\varepsilon$ is $44 \%$. However, a small amount of elliptic grain (III) is embedded in the austenite matrix, and the carbon content is $46.21 \%$ after two-pass rolling. The samples were ground and polished to the dense ribbon area of SS after wire cutting along the SS/CS bonding interface, and the phases were analysed by X'Pert PROMPD type X-ray diffraction (XRD). The XRD result of samples $1^{\#}$ and $2^{\#}$ shows two diffraction peaks of $\mathrm{M}_{2} \mathrm{C}$ in Fig. 5.

Table 2. The elemental composition of the different points

\begin{tabular}{|c|c|c|c|c|c|c|}
\hline Sample & point & $\mathrm{Cr}, \%$ & $\mathrm{C}, \%$ & $\mathrm{Ni}, \%$ & $\mathrm{Si}, \%$ & $\mathrm{Fe}, \%$ \\
\hline $1^{\#}$ & I & 17.54 & 11.15 & 5.56 & 1.28 & 64.47 \\
\hline $2^{\#}$ & II & 14.03 & 25.67 & 5.94 & 0.77 & 53.59 \\
\hline $3^{\#}$ & III & 10.07 & 46.21 & 4.17 & - & 39.55 \\
\hline
\end{tabular}

The peaks indicate that the streaks of sample $1^{\#}$ and $2^{\#}$ are carbide $\mathrm{M}_{2} \mathrm{C}$, and the matrix is austenite (as seen in Fig. 4). Furthermore, the peaks of sample $1 \#$ at $2 \theta=36.39^{\circ}$ and $2 \theta=80.93^{\circ}$ are weaker than that of sample $2^{\#}$, showing the higher quantity of carbide in sample $2^{\#}$. However, three austenite diffraction peaks are observed in the result of sample $3^{\#}$, which agrees with the microstructure of Fig. $4 \mathrm{c}$, and the components of the matrix are mainly austenite. Notably, no $\mathrm{M}_{2} \mathrm{C}$ was found in sample $3^{\#}$, unlike the composition of samples $1^{\#}$ and $2^{\#}$.

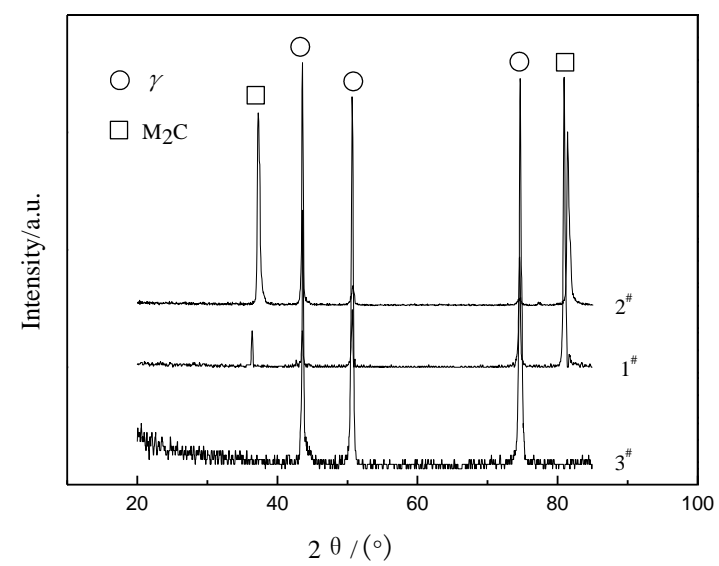

Fig. 5. XRD patterns of the dense ribbon area for the samples $1^{\# \text {, }}$ $2^{\#}, 3^{\#}$

\subsection{Microstructure of bonding interface}

Fig. 6 shows that the residual gas moved to the bonding interface and even produced micropores in the vicinal austenite grain. For particles in the micropore, elements are mainly $\mathrm{Cr}$ and $\mathrm{O}$, and the wt.\% of $\mathrm{O}$ and $\mathrm{Cr}$ are 48.33 and 52.67 according to EDS analysis. Therefore, we can conclude that the compound is $\mathrm{CrO}_{3}$. The austenite grain surface of the bonding interface is smooth and devoid of carbide streaks carbide, whereas the grain boundary is extremely clear (as seen Fig. 6 a). However, a small amount of granular carbides in the austenite near the bonding interface causes rough surface with an increase in $\varepsilon$ to $30 \%$ from Fig. 6 b. Fig. $6 \mathrm{c}$ shows the small austenite grain near the bonding interface is in accordance with the interior. No carbide was found in the matrix, and the surface is rough.

The SS/CS bonding interface of samples is detached using a special method, and the microstructure of SS bonding surface was analysed by XRD. The result shows that austenite and ferrite exist. A previous study [10] showed that the chromium atoms of SS diffuse into the surface of CS, forming carbide. A spot of carbide breakaway from CS adhere to the surfaces of sample $2^{\#}$ and sample $3^{\#}$ specimens. Thus, strong emergence was observed at $37.5^{\circ}$ in the XRD result (Fig. 7).

\section{DISCUSSION}

\subsection{Carbide precipitation}

Internal stress caused by $\varepsilon$ could induce phase transition, so that the carbide is precipitated in SS by VHRB. According to the following Clapeyron equation [11]:

$\frac{\mathrm{d} \sigma}{\mathrm{d} \ln \mathrm{T}}=\frac{\Delta \mathrm{H}^{1 \rightarrow 2}}{\Delta \mathrm{V}^{1 \rightarrow 2}}$,

where $\Delta H^{1 \rightarrow 2}$ is the phase change heat of austenite transformation to carbide; $\Delta V^{1 \rightarrow 2}$ is the volume change of austenite transforming into carbide.

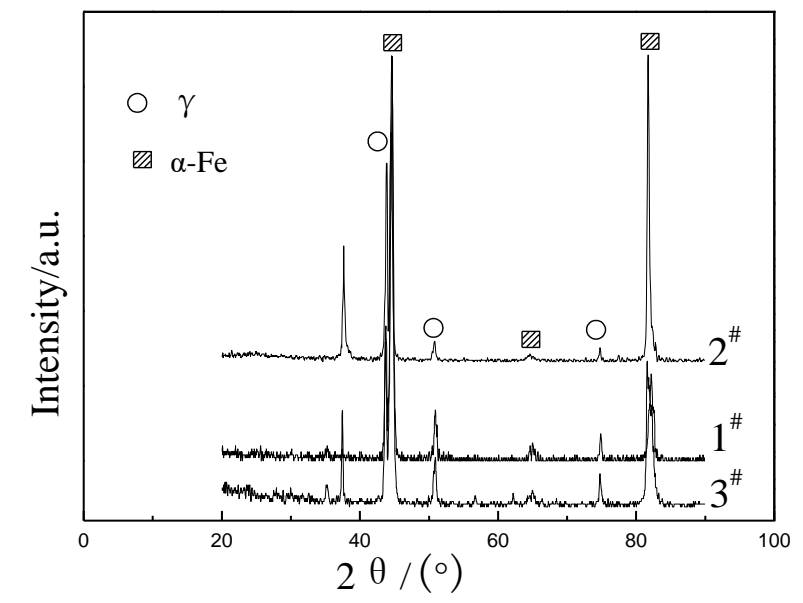

Fig. 7. XRD pattern of the bonding interface

The atom facilitated diffusion under the interaction of the temperature range $(\mathrm{d} \ln T)$ and the internal stress $(\sigma)$ that induced phase transition in the matrix.

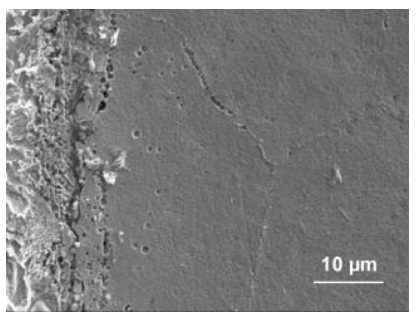

a

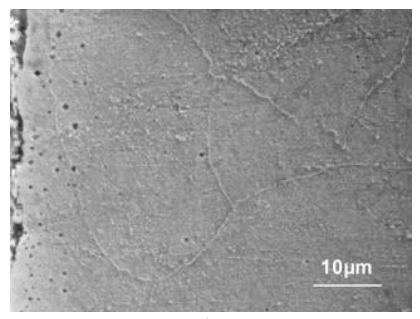

b

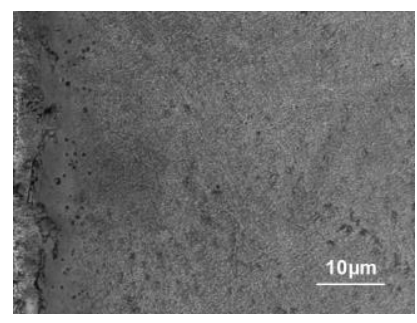

c

Fig.6. Interface microstructure of SS: a-sample $1^{\# ;}$ b-sample $2^{\#}$, c-sample $3^{\#}$ 
In a recent study [12], the large defect of grain boundaries, which is saturated with carbides and depleted of chromium, would first occur at the carbide-matrix interface. The intercrystalline internal stress of rolling promotes atom redistribution at high temperature. Therefore, part of the austenite is transformed into carbide $\mathrm{M}_{2} \mathrm{C}$ at the reduction rate of $20 \%$. However, the carbon content of $\mathrm{M}_{2} \mathrm{C}$ is low without removing the intercrystalline internal stress when the $\varepsilon$ is $30 \%$, and the defect of grain boundaries only absorbed considerably more carbon atom, forming higher carbon content carbide $\mathrm{M}_{2} \mathrm{C}$ than the former. The carbide $\mathrm{M}_{2} \mathrm{C}$ is formed in SS by hot isostatic pressing at about $1100{ }^{\circ} \mathrm{C}$ and is a metastable phase at high temperature [13]. Most of $\mathrm{M}_{2} \mathrm{C}$ disappeared and transformed into austenite again by internal stress after two-pass rolling, and a minimal amount of carbide particles were left in austenite (Fig. $4 \mathrm{c}$ ). The internal stress of single-pass rolling is the power to promote austenite transformation into carbide. The dispersal ability of carbon from the crushed grain is 15 times as much as the integrated ability [14]. Evidently, the dispersal ability of carbon is higher than the aggregation ability toward the defect in the crushed grain, in which the carbon atom is evenly distributed again and the defect energy of the matrix is reduced after the second rolling pass. However, the carbide concentrated in a few areas with the high defect energy after two-pass rolling, and the absorbed carbon atom filling defects include the precipitation of a small amount of elliptic particles at higher carbon content.

\subsection{Carbide distribution}

Dislocation density is related with $\varepsilon$, whereas the function of dislocation density in metal is associated with XRD coherent diffraction zone size $(d)$, lattice strain $(e)$, full width at half maximum $(\Delta 2 \theta)$ and so on. The equation could be written as follows [15]:

$$
\frac{(\Delta 2 \theta)^{2}}{\tan ^{2} \theta_{0}}=\frac{\lambda}{d}\left(\frac{\Delta 2 \theta}{\tan \theta_{0} \sin \theta_{0}}\right)+25\langle e\rangle^{2},
$$

where $\theta_{0}$ is the Bragg angle and $\lambda$ is the $\mathrm{Cu} \mathrm{K} \alpha$ wavelength.

The $d$ and $\langle e\rangle^{2}$ values could be calculated by linear regression analysis from Eq. 2.

The dislocation density could be determined according to the formula [15]:

$$
\rho=2 \sqrt{3}\left\langle e^{2}\right\rangle^{1 / 2}(d \times b),
$$

where $\rho$ is the dislocation density and $B$ is the Burgers vector.

The dislocation density of the midst $\left(\rho_{\mathrm{M}}\right)$ and the bonding interface $\left(\rho_{\mathrm{I}}\right)$ of SS are computed through the result of XRD (Fig. 5 and Fig. 7) in Table 3.

Microhardness is proportional to the dislocation density, as seen from the equation [16]:

$H=H V+a G b \rho^{\frac{1}{2}}$,

where $H$ is the material microhardness, $H V$ is the matrix microhardness and $G$ is the shear modulus.

The microhardness of the midst $\left(H V_{\mathrm{M}}\right)$ and the bonding interface $\left(H V_{\mathrm{I}}\right)$ of SS were tested by a HDX-1000 type micro-Vickers sclerometer, and the results are listed in Table 3. The result shows that the $H V_{\mathrm{I}}$ of the sample is considerably lower than $H V_{\mathrm{M}}$ and $\rho_{\mathrm{I}}$ is lower than $\rho_{\mathrm{M}}$; accordingly, the material microhardness of the midst is larger than that of the bonding interface.

Furthermore, microhardness is inversely proportional to the grain size, as seen from the equation [17]

$$
H=H V+K d^{-\frac{1}{2}},
$$

where $K$ is a constant and $d$ is grain size.

The non-binding surface at the middle two-layer SS of the clad plate was coated with a dense release agent particle. The surface of SS adjacent to CS became the outer surface. The hardness of the outer surface is lower than that of the interior because the expansion coefficient is higher with increasing temperature [18]. Then, the surface deforms easily during rolling progress, and the size of austenite grain becomes longer and larger with rising reduction ratio $(\varepsilon)$, whereas $\rho_{\text {I }}$ decreases. The value of $\rho_{\mathrm{M}}$ increases first and then decrease with rising $\varepsilon$ (Table 3 ), as the grain size of the midst becomes smaller, hardness increases and the dislocation density increases for single-pass rolling. In contrast, grain size becomes slightly larger because of the decrease in the nucleation number of recrystallization after two-pass rolling (as seen in Fig. 4), $H V_{\mathrm{M}}$ and $\rho_{\mathrm{M}}$ are reduced accordingly.

The stored energy of dislocations $\left(E_{\mathrm{D}}\right)$ is proportional to the dislocation density, as seen from the following equation [19]:

$$
E_{D}=c G b^{2} \rho,
$$

where $c$ is a constant.

The binding energy of $\mathrm{C}$-metal is higher than that of metal-metal, so the lattice binding energy of carbides is high in the austenitic section [20]. Thus, in accordance with the dislocation density, the stored energy in the midst is high. The high-energy carbide $\mathrm{M}_{2} \mathrm{C}$ is concentrated, and the bonding interface is devoid of carbide (Fig. 7). Thus, the range of the high-energy area (with high $\rho_{\mathrm{M}}$ ) could be determined by the area where carbide $\mathrm{M}_{2} \mathrm{C}$ has precipitated. The relationship of $\varepsilon$ and the range with high $\rho_{\mathrm{M}}$ is described in Fig. 8.

Table 3. The calculated and measured values

\begin{tabular}{|c|c|c|c|c|c|c|}
\hline Sample & $\rho_{\mathrm{M}} \times 10^{11} \mathrm{~m}^{-2}$ & $\rho_{\mathrm{I}} \times 10^{11} \mathrm{~m}^{-2}$ & $\mathrm{HV}_{\mathrm{I}}$ & $\mathrm{HV}_{\mathrm{M}}$ & $\mathrm{V}_{\mathrm{c}}, \%$ & $\sigma, \mathrm{MPa}$ \\
\hline $1^{\#}$ & 2.96 & 1.44 & 219.6 & 231.8 & 25 & 169.3 \\
\hline $2^{\#}$ & 9.47 & 0.6 & 192.3 & 258.5 & 35 & 200.8 \\
\hline $3^{\#}$ & 1.19 & 0.3 & 173.2 & 208.6 & 3 & 309.4 \\
\hline
\end{tabular}

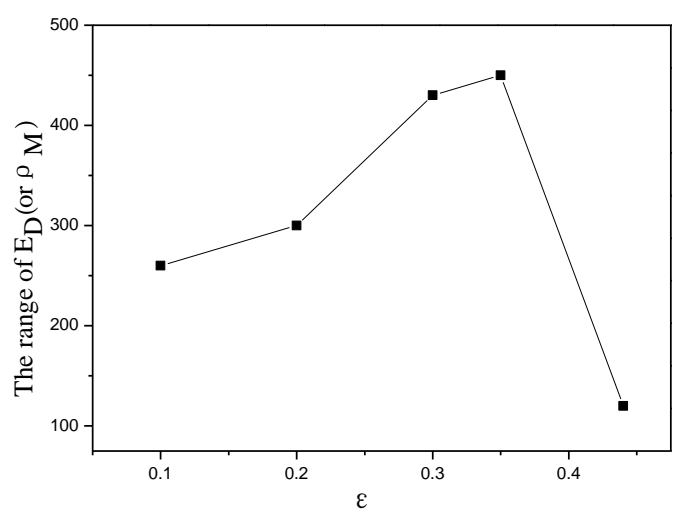

Fig. 8. Variation of the range of high-energy vs. $\varepsilon$ 
The range with high $\rho_{\mathrm{M}}$ increases with rising $\varepsilon$ because of grain boundary defects, which lead to the increase in the formation of carbide for single-pass rolling, whereas the range decreases rapidly with decreasing quantity of carbide after two-pass rolling.

The average volume fraction of $\mathrm{M}_{2} \mathrm{C}\left(V_{\mathrm{c}}\right)$ in the midst of SS layer is measured by an image analysis software, and the relationship among $\varepsilon, \rho_{\mathrm{M}}$ (or $E_{\mathrm{D}}$ ) and $V_{\mathrm{c}}$ are described in Fig. 9. We can observe that $V_{\mathrm{c}}$ and $\rho_{\mathrm{M}}$ increase with $\varepsilon$ for single-pass rolling but decrease rapidly after two-pass rolling. $V_{\mathrm{c}}$ is $25 \%$ when the reduction ratio is $20 \%$. The carbide percentage in the midst of SS layer increases to $35 \%$ with the increase in reduction ratio to $30 \%$, and $\rho_{\mathrm{M}}$ is approximately 3 times of the former. Moreover, carbide $\mathrm{M}_{2} \mathrm{C}$ in the midst of the SS layer mainly transforms into austenite again, only a small amount of carbide grains remains in the austenite and $\rho_{\mathrm{M}}$ or the stored energy is low.

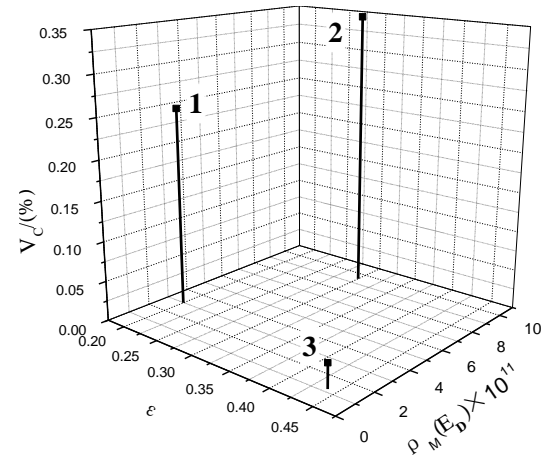

Fig. 9. Relationship among $\varepsilon, \rho_{\mathrm{M}}\left(E_{\mathrm{D}}\right)$ and $V_{\mathrm{c}}$

\subsection{Mechanical properties of clad plate}

Shear test was carried out to evaluate the bonding strength of the specimen, and shear strength is listed in the Table 3 . The reduction ratio of sample $1^{\#}$ is $20 \%$, with a pre-rolling temperature of $1084{ }^{\circ} \mathrm{C}$ and rolling force of $40 \mathrm{~T}$. The shear strength is $169.3 \mathrm{MPa}$. The reduction ratio is $30 \%$, so that the rolling force decrease by $1 \mathrm{~T}$ when the pre-rolling temperature increases to about $100{ }^{\circ} \mathrm{C}$, while the rolling force decrease $1 \mathrm{~T}$. The shear strength of sample $2^{\#}$ reaches to $200.8 \mathrm{MPa}$. The rolling force of the two rolling forces is $38 \mathrm{~T}$, total reduction is $44 \%$ and the shear strength of sample $3^{\#}$ rises by $50 \%$ compared with sample $2^{\#}$.

The SS fracture morphology of samples $2^{\#}$ and $3^{\#}$ are shown in Fig. 10.

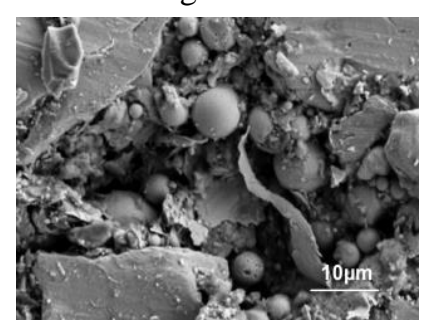

a

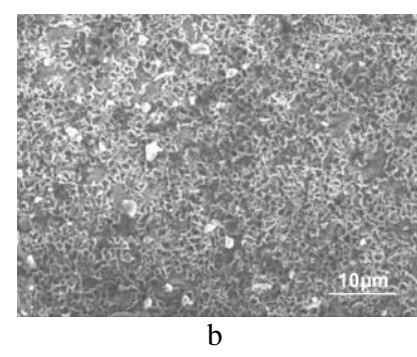

$\mathrm{b}$
Fig. 10. Fracture morphology of clad interface after stripping: $\mathrm{a}$ - sample $2^{\# ;} ; \mathrm{b}$ - sample 3

Sample $2^{\#}$ shows a rough fracture surface and numerous $\mathrm{CrO}_{3}$ particles with different sizes existing in the depth of fracture. We can deduce that oxide aggregation occurs in the VHRB process. Actually, the austenite grains are small and uniform around the fractograph, whereas the oxide that causes stress concentration becomes the fracture origin. Fig. $10 \mathrm{~b}$ shows that uniform dimples are distributed on the fracture interface and that the shear fracture surface is the interface of SS/CS. Furthermore, the dimples are salient under the action of shear force, and certain carbide particles are adhered on the surface. The experimental results show that the shear strength increases with rising $\varepsilon$ and is inversely proportional to $\rho_{\mathrm{I}}$. The results show that the grain of SS is obviously coarsened with rising $\varepsilon$ (Fig. 10), which is an important factor in increasing shear strength. Moreover, the slightly large grain size combined closely with CS is beneficial for the global stress on the bonding interface after two-pass rolling.

\section{CONCLUSIONS}

1. Carbide $\mathrm{M}_{2} \mathrm{C}$ precipitates in the interior of stainless steel, and carbon content increases with rising $\varepsilon$.

2. The dislocation density of the SS surface $\left(\rho_{\mathrm{I}}\right)$ is lower than that in the midst $\left(\rho_{\mathrm{M}}\right)$, and $\rho_{\mathrm{I}}$ decreases with rising $\varepsilon$. However, $\rho_{\mathrm{M}}$ increase first and eventually decreases with rising $\varepsilon$.

3. The dislocation density of bonding interface decreases due to the increasing size of austenite grain. Furthermore, high dislocation density is found in the midst, where the high energy of carbide $\mathrm{M}_{2} \mathrm{C}$ is concentrated for single-pass rolling, and the quantity of $\mathrm{M}_{2} \mathrm{C}$ increases with $\varepsilon$. Moreover, carbide almost disappeared as it transformed into austenite, and only a small amount of granular carbides are formed after two-pass rolling.

4. The results of shear fracture experiments show that the bonding strength increases evidently with the rising $\varepsilon$ and is inversely proportional to $\rho_{\mathrm{I}}$.

\section{Acknowledgments}

This work was financially supported by the National Natural Science Foundation of China (51205269) and (51404159).

\section{REFERENCES}

1. Hwang, Y.M., Tzou, G.Y. An Analytical Approach to Asymmetrical Cold- and Hot-Rolling of Clad Sheet Using the Slab Method Journal of Materials Processing Technology 62 1996: pp. 249-259.

2. Huang, Q.X., Yang, X.R., Ma, L.F. Interface-Correlated Characteristics of Stainless Steel/Carbon Steel Plate Fabricated by AAWIV and Hot Rolling Journal of Iron and Steel Research, International 2014: pp. $931-937$.

3. Wang, P., Lu, S.P., Xiao, N.M. Effect of Delta Ferrite on Impact Properties of Low Carbon $13 \mathrm{Cr}-4 \mathrm{Ni}$ Martensitic Stainless Steel Materials Science and Engineering A 527 2010: pp. 3210-3216. http://dx.doi.org/10.1016/j.msea.2010.01.085

4. Luo, Z.G., Xie, G.M., Wang, G.L. Effect of Interfacial Microstructure on Mechanical Properties of Vacuum Rolling Clad Pure Titanium/High Strength Low Alloy Steel Chinese Journal of Materials Research 27 2013: pp. 569-575. 
5. Sun, M.M., Chen, Z.Y., Bu, Y.Y. Effect of $\mathrm{ZnO}$ on the Corrosion of Zinc, Q235 Carbon Steel and 304 Stainless Steel Under White Light Illumination Corrosion Science 82 2014: pp. $77-84$.

http://dx.doi.org/10.1016/j.corsci.2013.12.022

6. Bulent, K., Adnan, Ç. Interface Structure of Diffusion Bonded Duplex Stainless Steel and Medium Carbon Steel Couple Materials Characterization 2009: pp. 1035 - 1040.

7. Yilamu, K., Hino, R., Hamasaki, H. Air Bending and Springback of Stainless Steel Clad Aluminum Sheet Journal of Materials Processing Technology 210 2010: pp. 272-278.

8. Hong, S.T., Kim, W., You, Y.J. Effect of Annealing on Two Different Niobium-Clad Stainless Steel PEMFC Bipolar Plate Materials Transactions of Nonferrous Metals Society China 19 2009: pp. 56-60. http://dx.doi.org/10.1016/S1003-6326(10)60245-2

9. Takuya, K., Akio, S. Evaluation of Deformation Behaviour of Oxide Scale in Hot Rolling Process by Vacuum Hot Rolling Mill Procedia Engineering 81 2014: pp. 126-131.

10. Li, H.B., Huang, Q.X., Zhou, C.L. Microstructure Evolution of Carbon Steel at Interface of Carbon Steel/Stainless Steel Clad Plate by Hot Rolling Transactions of Materials and Heat Treatment 35 2014: pp. 57-61.

11. Li, X., Ren, Z.M., Wang, L.L. Effect of High Magnetic Field on Phase Morphology and Transformation in $\mathrm{Bi}-6 \% \mathrm{Mn}$ Alloys Acta Metallurgica. Sinica 42 2006: pp. $77-82$. http://dx.doi.org/10.1016/S1672-2515(07)60239-5

12. Ahmedabadi, P., Kain, V., Arora, K. Radiation-Induced Segregation in Desensitized Type 304 Austenitic Stainless Steel Journal of Nuclear Materials 416 2011: pp. 335-344. http://dx.doi.org/10.1016/j.jnucmat.2011.06.024

13. Zhang, G.Q., Hua, Y., Jiao, D.L. Microstructure Evolution and Mechanical Properties of T15 High Speed Steel Prepared by Twin-Atomiser Spray Forming and Thermo-Mechanical Processing Materials Science and Engineering A $558 \quad$ 2012: pp. 566-571. http://dx.doi.org/10.1016/j.msea.2012.08.050

14. Kang, J.H., Rivera, D.C. Carbide Dissolution in Bearing Steels Computational Materials Science 2013: pp. $364-372$. http://dx.doi.org/10.1016/j.commatsci.2012.09.022

15. Xu, X.J., Song, T., Fan, Z. Microstructure and Dislocation Strengthening of Sc Microalloyed 2099 Al-Li Alloy Rare Metal Materials and Engineering 41 2012: pp. $621-624$.

16. Lu, J.Z., Luo, K.Y., Feng, A.X. Microstructural Enhancement Mechanism of LY2 Aluminun Alloy by Mean of a Single Laser Shock Processing Chinese Journal of Lasers 37 (10) 2010: pp. 2662-2666.

17. Yang, D.Z. Dislocation and metal Reinforcement Mechanism. Harbin Institute of Technology Press, Harerbin, 1991: pp. $128-131$.

18. An, G.Y. Theory of The Castings Formation. Harbin Institute of Technology press, Harbin, 1990: pp. 9-11.

19. Yan, F., Zhang, H.W. Evaluation of Stored Energy from Microstructure of Multi-Component Nanostructured $\mathrm{Cu}$ Journal of Materials Science \& Technology 28 2012: pp. 289-293. http://dx.doi.org/10.1016/S1005-0302(12)60056-5

20. Dai, Y.M., Wang, X., Liu, Y.X. Calculation of Cohesive Energy of Alloyed Austenite by Interatomic Pair Potential Journal of Dalian Maritime University 32 2006: pp. $96-100$. 